\title{
Metabolic Consequences of Skeletal Muscle Atrophy Caused by Space Flight Conditions
}

\author{
Irina M. Larina, $\mathrm{MD}, \mathrm{ScD}^{1}$; Irina V. Ogneva, $\mathrm{PhD}, \mathrm{ScD}^{1,2^{*}}$ \\ ${ }^{I}$ SSC RF Institute of Biomedical Problems of RAS \\ ${ }^{2} I . M$. Sechenov First Moscow State Medical University \\ Moscow, Russian Federation
}

\begin{abstract}
The review aims to analyze the relationship between metabolic changes in muscle tissue occurring in space flight conditions and other body systems during the developing atrophy. The data about the activity of various enzyme systems in muscles, liver and myocardium are presented. It was shown that during the transformation of postural muscles, metabolism from the lipid to carbohydrate, the activity of gluconeogenesis in the liver pathways is increased and the intensity of the oxygen consumption by the heart muscle changes.
\end{abstract}

Keywords: space flight; metabolic pathways; postural muscles; myocardium.

\section{Introduction}

During a space flight (SF), human activity takes place in unfavorable conditions that are a complex set of geophysical, technological and social factors. Their combination acts as a powerful incentive to adaptation, forming a new metabolic status, which gives the body a survival advantage in an unusual environment. Historically, the features of metabolism, the modification of metabolic pathways during the rehabilitation period after space flight, were studied most of all because of the limited technical possibilities to study the state of the metabolism during a flight $[1,2]$. Now, however, the available experimental data enables us to form a coherent image of the human metabolism adaptation state during a long flight in space. The necessary etiopathogenetic substantiation for the prevention of adverse changes in physiological systems during very long space missions provides the particular relevance for this analysis. The presented review mainly uses the experimental data relating to the state of the metabolic rate for a tissue level.

*Corresponding author: Prof. Irina V. Ogneva, PhD, ScD; SSC RF Institute of Biomedical Problems of RAS, 76-a Khoroshevskoyoe shosse, Moscow, 123007, Russian Federation; I.M. Sechenov First Moscow State Medical University, 8/2 Trubetskaya str., 119991, Moscow, Russian Federation.E-mail: iogneva@yandex.ru
The theoretical assumptions for the analytical development of a coherent image of the adaptive metabolic rate, which is formed during a SF, are the classic physiology and biochemistry propositions. Since almost all metabolic reactions in a body are interconnected, the product of one enzymatic reaction may be the substrate for the one that plays a role in the next stage. Metabolism is an extremely complex network of enzymatic reactions, binding all body tissues to organ cycles. Moreover, if the stream(s) of substrates in any one part of the network is(are) modified, the changes in the other part of the network will take place so that the first change is balanced or compensated. The speed of the process is regulated in accordance with the current needs of the body, tissues and cells on any of the central metabolic pathways - a catabolic or anabolic one. At the same time, all the reactions are adjusted so that they are carried out most economically, i.e., with the least possible expenditure of energy and matter. Although anabolic and catabolic pathways are not identical, they are connected by organ cycles by the common amphibolic stage (citric acid cycle and some auxiliary enzymatic reactions). This stage of metabolism performs a dual function. It is used not only for the oxidative catabolism, i.e. for the breakdown of carbohydrates, fatty acids and amino acids, but also serves as the first stage of many biosynthetic pathways for which it is the source of precursors.

The muscle tissues have a special importance in space 
medicine and gravitational physiology for several reasons. First of all, muscles are the largest tissues in the body: their weight makes up about $30 \%-40 \%$ of the total body weight, and the main metabolism makes up $25 \%$ of the body's metabolism. Besides, muscle tissue is the main producer of energy and, finally, it is gravitationally dependent. Since the muscle tissue is included in the basic metabolic cycles of organs (glucoselactate, pentose-phosphate, glucose-alanine cycle, urea cycle) which bind it (by substrate flows) with the liver, kidneys, myocardium, and brain, the effects of developing atrophy should inevitably affect the metabolism of the whole body, and in particular the energy substrate and precursor molecules exchange (used for the biosynthesis of amino acids, fatty acids and carbohydrates).

This review is an attempt to analyze the impact of the changed metabolism of muscle tissue on the metabolism of other body systems, especially on the cardiovascular system, as one of the altered gravity (gravity discharge) action targets during SF.

\section{Muscle tissue}

It is shown that during the real or simulated gravity discharge, atrophic changes in the skeletal muscle fibers of mammals and people develop [3]. The contractile performance of the muscle fibers decreases and they become more rigid [4-7]. The cross-sectional area of muscle fibers decreases $[8,9]$, and the myosin phenotype transformation rate increases $10,11]$. Additionally, there are changes in the contractile protein content [12] and the amount of myofibrillar apparatus [13,14]. These changes lead to a decrease in the efficiency of postural muscles, which significantly complicates the implementation of long-term space flights and the rehabilitation period after their completion.

The experiments on rats showed that skeletal muscle fatigue caused by the real or simulated gravity discharge, partly due to the increased reliance on carbohydrate metabolism, which in turn is due to a lower capacity for oxidation of triglycerides $[15,16]$. Thus, the example of the rat lateral vastus muscle fibers demonstrated that a nine-day spaceflight led to a decrease of $37 \%$ in fatty acid oxidation [15]. It is also known that the functional discharge led to an increase in the number of "fast-twitch" fibers in soleus muscles from about $15 \%$ to $30 \%[17,18]$. The elevated levels of glycogen in the muscle may be the result of an increase in "fast-twitch" muscle fibers, which are glycolytic. However, on the other hand, the gravity discharge may affect metabolism in such a way that causes the consumption of glycogen to increase in "slow-twitch" type muscle fibers.

The glycogen content increase, according to the literature $[19,20]$, reaches its maximum during the first days of antiorthostatic hanging. In this case, the amount of the substrate increase was not affected by a decrease in the glucose consumption rate. The authors suggest that such an increase in glycogen levels was associated with decreased contractile activity during the hanging, which caused inhibition of the glycogen phosphorylase and therefore slowed the glycolysis process [20]. Furthermore, the increased glycogen content in the slow muscle fibers could be explained by selective degradation of contractile proteins resulting in increased concentrations of other chemical cells, in particular glycogen $[21,22]$. However M.G.Tavitova et al. [23] showed that the glycogen volume in the rat soleus muscle after a three-day discharge was significantly reduced in the fast and a slow fibers, although the restoration up to control values took place on the $14^{\text {th }}$ day.

It was shown that five-day gravity discharge resulted in an increased insulin-stimulated glucose uptake [24]. The increase in glycogen content was noted in the soleus muscle of rats after a seven-day space flight of the Spacelab biosatellite [25]. Furthermore, a 14-day stay in weightless conditions led to an increase in hexokinase activity in the postural muscles of rats [26], and the antiorthostatic hanging of the same period led to an increase in glycogen content [27]. V. Grichko et al. [28] determined the content of energy substrates in the $m$. soleus fibers of monkeys exposed to 18-day immobilization. Prior to the immobilization the glycogen concentration was significantly higher in the type II fibers compared with slow type I fibers. These data are consistent with the results obtained in the experiment, during which we measured the glycogen in the fibers of the general human thigh muscle [29]. After a period of immobilization, there were no significant differences in the content of monkey soleus muscle fiber substrates.

R.H. Fitts et al. [30] performed an experiment that compared the level of glycogen in the soleus muscle fibers of a man after a 17-day space flight and after a 17-day hypokinesia in a bed. After hypokinesia, the glycogen level, as well as the content of phosphorylase and hexokinase, increased equally in slow and fast (IIa) muscle fibers [31]. However, after the space flight there were no significant changes in the glycogen content of type I fibers, and the glycogen levels of IIa-muscle fibers even decreased [30]. The authors suggest that the reason for the absence of the expected glycogen level increase in the fibers of the soleus muscle of a man after a space flight could be the astronauts' lack of energy consumption. The energy value of astronaut dietary intake was $24.6 \pm 3.3 \mathrm{kcal} / \mathrm{kg}$ per day, resulting in an average loss of $2.6 \mathrm{~kg}$ body weight by astronauts. However, an increase in lipid content was observed in the fibers of the soleus muscle after the space flight [7]. In addition, X.J. Musacchia et al. [34] showed that the triglyceride reserves increase in the rats' broad thigh muscle after a 14-day space flight as compared to hung animals.

M.G. Tavitova et al. [23] found that the triglyceride content in the slow fibers of rat soleus muscle was almost unchanged after 3 and 14 days of antiorthostatic hanging of rats. The fast type fibers showed a tendency toward an increase in triglycerides after three days of hanging and a tendency toward a decrease after two weeks of discharge. The change of intracellular substrates reserve levels in microgravity conditions may be related to the modulation of energy consumption when muscle contractile activity is reduced and the cellular respiration process is transformed, which depends on the activity of the Krebs cycle enzymes, the state of the electron transportation chain and mitochondrial membrane permeability for ADP.

The impact of weightlessness on the cellular respiration 
of rat skeletal muscle mitochondria was studied by exposing the animals to biosatellites. For example, E.S. Mayilian et al. [35] studied the tissues of rats exposed to weightlessness for 18.5 days on biosatellite Kosmos-1129. It was shown that after the biosatellite flight there was a significant decrease in the respiration rate of mitochondrial suspension extracted from the posterior thigh muscle group. The respiratory depression was clearly expressed both before and after the addition of ADP in the incubation medium, as well as at the succinate and $\alpha$-ketoglutarate oxidation. In addition, a decrease in the phosphorylation rate associated with the increased phosphorylation period was observed. On the sixth day of the readaptation period, the respiration rate was lower than after the exposure to weightlessness. Only after 29 days of the flight, was complete restoration of the respiration rate observed after measuring respiration values. By the sixth day of readaptation, the respiration parameters among the animals of the synchronous ground experiment group were not just recovered, but also exceeded the control values. Besides the activity of malate dehydrogenase and isocitrate dehydrogenase, a 1.5-2 times decrease was also found in mitochondria suspension isolated from rat hind limb muscles. This fact may indicate insufficient intake of restoration equivalents from the citric acid cycle into the mitochondrial electron transportation chain, which may be a reason for the decrease in oxygen consumption during cellular respiration. It was also found that after six days of flight the isocitrate dehydrogenase and malate dehydrogenase and isocitrate dehydrogenase activity in mitochondria was restored to control values [35].

In situ studies showed that the maximum oxygen intake by the outer broad thigh muscle of two monkeys exposed to weightlessness for 15 days was significantly reduced by $28 \%$ and $32 \%$, respectively [36]. After two days of the rat having its hind limbs immobilized, there was a significant decrease in the respiratory rate $(37 \%)$ in subsarcolemma mitochondria isolated from the gastrocnemius muscle [37]. It was also shown that 28 days of antiorthostatic hanging led to a respiration rate decrease in a metabolic state to $59 \%$ in the gastrocnemius muscle fibers of a rat (addition glutamate and malate acted as substrates). There were no significant differences from control when succinate and rotenone were used as respiration substrates. The obtained data lead to the conclusion that the gravitational discharge for 28 days has an effect on mitochondrial respiration of the gastrocnemius muscle fibers and, apparently, affects the respiratory chain complex I (NADH-CoQ-reductase) or any chain section preceding this complex [38]. It should be noted that at such impact periods the citrate synthase activity, Krebs cycle enzyme, catalyzing the formation of citrate from oxaloacetate and acetyl-CoA, is decreased [39].

The impact of long-term gravity discharge (antiorthostatic hanging for 35 days) is that it leads to reduction, after discharge, in the rate of oxygen consumption in the soleus muscle fibers of endogenous and exogenous substrates. It may be associated with the transition to the glycolytic pathway of energy consumption due to the reduced EMG activity. The absence of an effect from increasing the respiratory rate while adding exogenous substrates was also noted as compared to endogenous substrates in the m.soleus fibers. This fact, as well as F. Yajid's et al. results [39] may indicate a breach in the first complex of the respiratory chain operation - NADH-coenzimQ-oxidoreductase [38].

However, the impact of the enzyme activity of the Krebs cycle on the process of cellular respiration may be evident when the state of the respiratory chain remains intact. There is evidence of a decrease in cytochrome oxidase activity in rat soleus muscle fibers $[40,41]$. Furthermore, cellular respiration depends on mitochondrial membrane permeability, which is regulated mainly by cytoskeletal proteins [42]. Perhaps one of these proteins is desmin, which was shown in experiments with zero-desmin mice $[43,44]$. It was found that the oxygen absorption intensity by soleus muscle fibers and the dissociation constant of ADP are significantly reduced among mice with the desmin knockout gene as compared to the same indices among normal mice [44]. It is also known that the mitochondria are in close association with the cytoskeletal desmin protein filaments that determine their location in the cell [44-46] and, possibly, are involved in ADP and creatine transport regulation through the outer mitochondrial membrane [42]. As desmin influences the mitochondria distribution and function, we may assume that the changes in the content of this protein under gravity discharge conditions and after the restoration may be correlated with the dynamics of cellular respiration parameters.

We have previously shown that the desmin content in rat soleus muscle fibers is reduced after 3 days of antiorthostatic hanging and reaches its minimum after 7 days, and in 12 days it almost does not differ from the control level [7]. At the same time, desmin content is also reduced during the early stages of rehabilitation after antiorthostatic hanging [47]. The analysis of cell respiration intensity dynamics at different stages of recovery and hanging showed that the rate of cell respiration is reduced at the same time when desmin content decreased [48].

Among other things, the intensity of cellular respiration may be influenced by the structural condition of the cortical cytoskeleton. One of the proteins forming a submembrane cytoskeleton is an actin-binding protein, alpha-actinin-4. We showed that during the earliest stages of gravitational discharge, the fibers of the shank muscles experience this protein dissociation from the cortical cytoskeleton $[49,50]$. By taking into account the results of S. Goffart et al. [51] showing that alpha-actinin-4 may be related to the promoter region of the cytochrome $\mathrm{c}$ gene, resulting in a change in its expression, one may assume that it may also affect the efficiency of cellular respiration.

Thus, summarizing the published data one may assume that metabolism of the fast muscle fibers containing few mitochondria becomes the determining factor of the nature of metabolism for the whole muscle tissue. The fast muscle fiber type is primarily dependent on internal reserves of carbohydrate substrates. Glycolysis is very effective for high-intensity, short-term acute activity, but when the glycogen reserves necessary to perform physical work begin to decrease, the fat sources of energy are used as a rule. Anaerobic glycolysis is its ATP source, and the work intensity and duration is mainly dependent on the glycogen reserves. Obviously, the 
transition to the metabolism inherent in fast fibers reduces the dependence of working muscle tissue on the effectiveness of oxygen delivery by the cardiovascular system.

It is known that the products of glucose breakdown play an important role as precursors, and as intermediates of other metabolic cycles, so the regulatory enzymes of carbohydrate breakdown also reveal the respective signals of other metabolic pathways, and respond to these signals. This fact is another reason (besides the existence of organ metabolic cycles) for the adaptive involvement of other organs (especially the liver) in the metabolic adjustment, started by muscle atrophy and the transformation of muscle energy metabolism.

\section{Liver}

A man's liver and muscles are constantly exchanging with substrates. Glutamine, alanine (as the carriers of ammonia), and pyruvate are coming from muscles; free fatty acids, glucose, and amino acids come from the liver into muscles. The liver distributes substrates between organs, requiring its continuous supply to perform its functions. However, these organs do not have reserves and/or necessary enzyme systems for their local formation. Thus, the cardiac muscle, which consists of fibers inherent in all types of aerobic metabolism, has no glycogen or lipid reserves. However, its metabolism in normal conditions is provided with free fatty acids (and ketone bodies) at the ratio of $1 / 3$ and glucose at the ratio of $2 / 3$. Another organ, critically dependent on substrate provision from the liver is the brain, which performs its energy metabolism almost exclusively on the glucose imported from the liver and, partially, on $\beta$-hydroxybutyrate. Therefore, the changes of metabolic cycle that connect muscle and liver influence the flow of substrates from the liver to the heart and brain. In this regard, it is crucial to understand hepatic metabolism changes under space flight factors.

Normally, the liver (and the kidneys, adrenal glands, and erythrocytes) experience an active pentose phosphate cycle, supplying NAD-H and ribose-5-phosphate. The excess of fatty acids inhibiting glycolysis and pyruvate oxidation in the Krebs cycle activates the pentose phosphate pathway of glucose secondary catabolism. It is shown that the liver of rats after a space flight has decreased activity of aconitase and NADF-isocitrate dehydrogenase in mitochondria, NADmalate dehydrogenase and NAD-isocitrate dehydrogenase in the hepatocyte cytoplasm [30,52,53].

It is shown that the glycolytic metabolic pathway in the liver of hung rats does not undergo any changes; however, there is very clear evidence of an increase in enzyme gene expression involved in gluconeogenesis. All enzymes of flight-group rats involved in the regulation of gluconeogenesis, increase their activity (pyruvate carboxylase, phosphoenolpyruvatecarboxykinase, glucose-6-phosphatase, fructose 1,6-dyphosphatase) $[54,55,56]$. The activation of phosphoenolpyruvatecarboxykinase indicates the usage intermediates of the Krebs cycle along with pyruvate as glucose precursors. The increase in the intensity of gluconeogenesis in the liver is stimulated also by the excess availability of amino acids [57-60] secured mainly by the reduction of muscle tissue remodeling upon activation of liver aminotransferases $[52,53,61,62]$. At the same time, the activity of enzymes involved in fatty acid synthesis was reduced, indicating reduction in the liver lipogenesis [26, 63-66].

It is believed that the enhanced secretion of glucocorticosteroids causes the mobilization of glycogenic amino acids in peripheral tissues, which promotes gluconeogenesis, glucose increasing the glucose progenitor pool and simultaneously activating aminotransferase. The increased activity of 3-aminotransferase tyrosineaminotransferase (TAT), aspartate aminotransferase (AST) and alanine-aminotransferase (ALT) was regularly observed in the liver of flight rats, and AST and ALT were regularly observed in blood [54,67-69]. At the same time after the biosatellite Cosmos-782 flight, the ALT in the liver of rats remained unchanged $[54,56]$.

The accumulation of glycogen in the liver, myocardium and muscle tissues was regularly observed among rats after the SF of different periods [56,67-71], despite the absence of marked glycogen synthase activity changes. The liver enzyme activity was reduced after the flight of "Cosmos-936" biosatellite, but remained unchanged after the flight of "Kosmos-1129" biosatellite.

The liver of flight-group animals had high tyrosine, triptofanpirrolaze and serindehydrotase activity. The white and brown adipose tissues had increased levels of free fatty acids, the liver and thymus had increased levels of triglycerides, and the blood plasma had an increased concentration of both lipid metabolism components [54,55]. A surplus of lipid peroxidation products and the activation of the antioxidant defense system were discovered also in the liver [72].

Along with the increased concentration of free fatty acids in blood and tissues [73], the enhancing of lipolytic processes was confirmed by the increase of triglyceride lipase activity, detected in the white adipose tissue of rats. In the latter case, there was an increase not only of the basal activity but also of hormone-stimulating lipolysis activity.

The increase of free fatty acids in the tissues and blood contributes to their decrease in oxidation, as indicated by 3-hydroxyacyl-CoA dehydrogenase activity suppression, found in the soleus and triceps muscles of rats after a flight [56,67,73-75]. In its turn, the excess of fatty acids inhibiting glycolysis and pyruvate oxidation in the Krebs cycle activates the pentose phosphate pathway of glucose metabolism. These statements are in good agreement with the data on the reduction of aconitase and NADF-isocitrate dehydrogenase activity in flight animals' liver and mitochondria, and of NADmalate dehydrogenase and NADF-isocitrate dehydrogenase in the hepatocyte cytoplasm $[56,67]$.

There was a reduction of the glucose-6-phosphatase and decarboxylated NADF malate dehydrogenase in the liver $[68,69,76]$. The role of malate dehydrogenase is not limited by its participation in gluconeogenesis, since the enzyme provides the formation of NADPH cofactor, which is used for the biosynthesis of fats. Therefore, reduction of this enzyme activity may be indicative of lipogenesis inhibition, as evidenced by the activity decrease of enzymes involved in the biosynthesis of fatty acids, phospholipids, 
and triglycerides (ATP-citrate lyase, diglierid acyltransferase, phosphatidilholy-phosphoglyceride-acyltrans-transferase). At that, there were no changes in the activity of beta-hydroxybeta-methylglutaryl-CoA-reductase, which provides the biosynthesis of cholesterol. Many tissues of flight rats were characterized by triglycerides increase $[54,56,73]$.

The cholesterol content in the liver was not changed, as a rule. But an increase in it was detected only after the flight of the Space-936 biosatellite, where there was a regular cholesterol increase in blood plasma $[56,67,73]$.

Thus, the data in the literature suggest that the need of glucose acceptors in this energy substrate increases in weightless conditions. Thus, the liver extensively uses for its formation the non-carbohydrate precursors (lactate, pyruvate, glycerol, amino acid, oxidation intermediates of the citric acid cycle). Given that the efficiency of the heart muscle is largely dependent on glucose (about 65\%), while the level of its synthesis by the liver increases, it is reasonable to assume that the level of energy metabolism in the myocardium increases in microgravity conditions, but on the other hand, the consumption of this substrate by muscle tissue is also increased.

\section{Myocardium}

Staying in microgravity conditions leads to various changes in the cardiovascular system of a person; shifts in the volume of bodily fluids volume start in the cranial direction during the acute period $[77,78]$ and the change of heart stroke volume [79-81].

In order to model the majority of effects identified in one's body in the conditions of weightlessness, the model of antiorthostatic hanging by tail is used among rodents, particularly among rats. It is shown that the effects characteristic for muscle and bone tissues in microgravity conditions are well reproduced in such ground-based experiments using antiorthostatic hanging $[82,83]$.

However, data on changes in the cardiovascular system are contradictory. Most researchers state the redistribution of fluids and the presence of hypovolemia among rats under antiorthostatic hanging conditions $[35,84,85]$. At that, F.G. Shellock et al. [86] showed that the rate of change depends on the angle of hanging. Thus, the central venous pressure was increased among rats hung under an angle of $45^{\circ}$ and an angle of $20^{\circ}$. In the first case, the consistency was already higher than in the second one after eight hours of hanging. At that, the values of parameters did not differ from the control group of rats hung at an angle of $20^{\circ}$ after 24 hours of hanging while values for the group of rats hung under an angle of $45^{\circ}$ was significantly higher than those for the control group [86]. The effects of the early period, in turn, led to a volume load increase on the heart by the cardiopulmonary receptors activation [87].

By analyzing the intensity of cellular respiration of the rat cardiomyocytes during the early stages of antiorthostatic hanging, we showed that the basal rate of cardiomyocyte cell respiration among experimental animals remained virtually unchanged during the experiment, slightly, albeit consistently increasing during the first day. This may indicate an increase in the availability of endogenous substrates, such as glucose, which is consistent with our assumption. At that, the respiration rate added to glutamate and malate medium, and the maximum respiration rate was significantly increased after day 1 and remained as high up to 14 days. At that, in 3 days of recovery after a 14-day antiorthostatic hanging, all these parameters were significantly decreased compared with the control level [49]. The preferential increase of the maximum respiration rate and the respiration rate on the endogenous substrates indicates that the number of mitochondria and/or the concentration of respiratory chain complexes in these mitochondria may be increased. At that, the number of endogenous substrates was possibly decreased by the third day of hanging as a basal respiration rate. This hypothesis is confirmed by the increase of desmin content in rat cardiomyocytes under antiorthostatic hanging conditions [49], which are necessary to determine the localization of mitochondria and the regulation of their membrane permeability, as well as the data on the content increase of other oxidative enzymes and mitochondrial creatine kinase [88].

The longer effects lead to the cellular respiration intensity of cardiomyocytes beginning to decrease to the control level. A.X. Bigard et al. [89] found no change in the intensity of cell respiration in rat cardiomyocytes after 3 -weeks of antiorthostatic hanging. Yin et al. [90] and Cui et al. [91] showed that after four weeks of hanging, the mass of the rat heart and the blood pressure did not change, but the left ventricle pressure was reduced. In addition, the sensitivity of pressosensitive reflex remained unchanged after a 14-day hanging [92]. These data indicate that the acute period effects have already been compensated.

At the same time there is evidence of a decrease in myocardial contractility among rats as the result of a long hanging [93-95], along with oxygen consumption and a reduction of myocardial contractility $[14,96]$.

Thus, returning to the metabolic and energy situation in the body in terms of myocardium provision with the plastic and energy resources, we may conclude that there is an increase on the heart volume load and a marked increase in mitochondrial enzyme activity during the early stages of gravitational discharge. Later, during a prolonged stay in an antiorthostatic hanging, although the heart weight and blood pressure changes were not observed among experimental animals, the central venous pressure decreased. We also observed a decrease in the contractile capacity of the myocardium, including individual cardiomyocyte. During the long-term modeling of gravity discharge myocardial oxygen consumption fell, indicating a decrease in metabolism level for this tissue.

\section{Organism energy exchange}

The body's energy balance is closely related to the energy substrate flow modification and with the plastic metabolism changes. The orbital station Mir revealed more than a $50 \%$ decrease in the protein synthesis rate and an energy consumption reduction by $25 \%$, compared with the pre-flight animals [32]. The energy consumption in these missions made $\left(26 \pm 2.4 \mathrm{kcal}^{\mathrm{kg}}{ }^{-1} \mathrm{~d}^{-1}\right)$, which resulted in an negative energy 
balance [32]. The lower level of energy consumption $(24.4 \pm$ $\left.2.4 \mathrm{kcal}^{\mathrm{kg}}{ }^{-1} \cdot \mathrm{d}^{-1}\right)$ was observed during LMS flights [33]. The deficit of energy consumption, along with the reduction of the gravitational load on the musculoskeletal system are two of the top three causes of astronaut body weight loss during longterm flights [97]. Based on the meta-analysis of the data at the LSAH database (NASA's longitudinal study of astronaut health (LSAH) data base), A.K. Matsumoto et al. [98] concluded that if the loss of an astronaut's body weight during a flight will continue linearly at the rate currently observed on the ISS, the clinically significant weight-loss data (10\% or more) will be observed as early as the second year of future long-term missions. According to T.P. Stein, the body weight loss of this level that is caused by a deficiency in energy consumption may no longer be compensated by a one's body [99].

Additionally, A.K. Matsumoto et al. [100] concluded in their analysis that the higher the level of an astronaut's physical fitness at the beginning, the greater the weight loss during his flight. This may be explained by the fact that the increase in astronaut muscle mass during the preflight period will lead to an alteration in the metabolic status of greater number of muscle cells, that is, will be transferred to the glycolytic type of metabolism and as a result, the needs of pretrained astronaut muscle tissue in glucose will increase compared with those astronauts who have not conducted special training before the flight. Moreover, the basal level of myocardial needs in energy substrates among trained astronauts is also higher. Consequently, the pretrained astronauts will need to increase the supply of organ cycles with energy substrates. The terms of protein metabolism reduction in muscles and an inadequate inflow of energy substrates from outside (during a flight) form the image of energy deficiency in all tissues of the body associated by organ metabolic cycles with the liver and muscles. Thus, the physical activity increase in the course of training in space flight conditions, aimed at the muscle skeletal system support, will lead to a greater deficit [99].

In general, a vicious circle is established: the myocardium and muscle tissue increase their glucose requirements, while the energy substrate supply decreases from outside. Consequently, the body energy reserves are depleted, which may lead to a malfunction of cardiovascular and other body systems. Thus, T.R. Stein and A.K. Matsumoto believe that the inability to maintain an astronaut energy balance will become an increasingly important health problem during long and extremely long missions [98-100].

\section{Conclusion}

Under space flight conditions, despite the sharp decline of muscle activity (lack of body weight, small volume of movements), it is necessary to keep physical performance at the highest possible level to perform extravehicular activities, carry out the necessary work at the station (e.g., repairing) and ultimately to return to Earth. The astronauts who will fly to other planets, a chore that requires functionally active muscles, will also need to be strong enough to move in a space suit, even if the magnitude of the gravitational field will be only $1 / 3$ or $2 / 3$ of the Earth's gravity (as on the Moon or Mars).
The essential problem is to maintain not only the normal functioning of muscles, but also the normal functioning of the cardiovascular system.

Regarding the development of an adaptive functioning pattern, both systems are closely related to each other. Myocardium and muscle tissue have the primary effects of hypogravity actions that are associated with the rearrangement of cells due to changes in external mechanical stress. On the one hand, in the early stages of a flight the heart load increases, resulting in intracellular mechanical transduction, which may lead to the intensification of the cell respiration processes as it takes place in laboratory animals during antiorthostatic hanging. Consequently, the energy substrate needs are increased. On the other hand, as the result of direct interaction between muscular cells and mechanical fields, as well as indirect interaction caused by the changes in the level of neural stimulation, the gene expression pattern changes with the consequent increase of fiber content with the provision for the glycolytic type of substrate energy products. The change of muscle tissue metabolism, as the most significant mass and metabolically active tissues in a body, cannot affect the metabolism of other functional systems and organs. It is obvious that the decrease in the rate of muscle tissue exchange within the muscle tissue, particularly in postural antigravity muscles, and the transition from lipid to carbohydrate metabolism requires an increase in the gluconeogenesis level in the liver. However, the heart muscle also consumes glucose. With the deficiency of energy consumption during a space flight, this substrate may be depleted, which, in turn, will lead to a decrease in efficiency for the postural muscles that were transited to carbohydrate metabolism and myocardium, for which the carbohydrate metabolism is the dominant one. For this reason, an increase of physical exercise, requiring an even greater increase in the number of incoming energy substrates in space flight conditions (i.e., when there is an energy consumption reduction from the outside, with food) will lead to a greater deficit in a body.

In view of all facts mentioned above, it appears that the development of effective methods for preventing the negative effects on an astronaut staying in weightless conditions should be based both on the use of cell protection means to reduce the external mechanical stress (for example, ensuring the structure of the cortical cytoskeleton support by pharmacological modulation of the biological membrane properties and stimulating the expression of actin-binding proteins) and to take into account the basic principles of regulating the relationship among metabolic effects in various systems of the body, including the development of a negative protein and energy metabolism under SF conditions.

\section{Competing interests}

The authors declare that they have no competing interests.

\section{References}

1. Popova IA, Vetrova EG, Zaĭtseva LB, Larina ON, Markin AA, Fedotova NIu. Metabolism in cosmonauts: the results of biochemical research on the blood of the crew members 
of the 7 prime expeditions on the Mir orbital space complex. Aviakosm Ekolog Med 1992; 26(4):35-9.

2. Grigoriev AI, Egorov AD. Physiological aspects of adaptation of main human body systems during and after spaceflights. Adv Space Biol Med 1992; 2:43-82.

3. Kozlovskaia IB, Grigor'eva LS, Gevlich GI. Comparative analysis of the effect of weightlessness and its model on the velocity-strength properties and tonus of human skeletal muscles. Kosm Biol Aviakosm Med 1984; 18(6):22-6.

4. McDonald KS, Fitts RH. Effect of hindlimb unloading on rat soleus fiber force, stiffness and calcium sensitivity. J Appl Physiol 1995; 79:1796-1802.

5. Toursel T, Stevens L, Granzier H, Mounier Y. Passive tension of rat skeletal soleus muscle fibers: effects of unloading conditions. J Appl Physiol 2002; 92:1465-72.

6. Widrick JJ, Knuth ST, Norenberg KM, Romatowski JG, Bain JL, Riley DA, et al. Effect of a 17 day spaceflight on contractile properties of human soleus muscle fibres. J Physiol 1999; 516:915-30.

7. Ogneva IV. Transversal stiffness of fibers and desmin content in leg muscles of rats under gravitational unloading of various durations. J Appl Physiol 2010; 109:1702-9.

8. Oganov VS, Skuratova SA, Murashko LM, Shirvinskaia MA, Siladi T. Change of composition and properties of myofibrillar proteins after space flight. Biofizika 1982; 1:2630 .

9. Riley DA, Bain JLW, Thompson JL, Fitts RH, Widrick JJ, Trappe SW, et al. Thin filament diversity and physiological properties of fast and slow fiber types in astronaut leg muscles. J Appl Physiol 2002; 92:817-25.

10. Caiozzo VJ, Baker MJ, Herrick RE, Tao M, Baldwin KM. Effect of spaceflight on skeletal muscle: mechanical properties and myosin isoform content of a slow muscle. J Appl Physiol 1994; 76:1764-73.

11. Edgerton VR, Zhou M, Ohira Y, Klitgaard H, Jiang B, Bell $\mathrm{G}$, et al. Human fiber size and enzymatic properties after 5 and 11 days of spaceflight. J Appl Physiol 1995; 78:1733-9. 12. Chopard A, Pons F, Marini J. Cytoskeletal protein contents before and after hindlimb suspension in a fast and slow rat skeletal muscle. Am J Physiol Regulatory Integrative Comp Physiol 2001; 280:323-30.

13. Kozlovskaya IB, Shenkman BS. Muscle Structure and Metabolism. Space Biology and Med Joint US Russian Publication 1996; 3:231-46.

14. Desplanches D, Mayet M, Sempore B, Flandrois R. Structural and functional responses to prolonged hindlimb suspension in rat muscle. J Appl Physiol 1987; 63:558-63.

15. Baldwin KM, Herrick RE, McCue SA. Substrate oxidation capacity in rodent skeletal muscle: effects of exposure to zero gravity. J Appl Physiol 1993; 75:2466-70.

16. Heywood-Coolsey A, Fitts RH. The effect of hindlimb suspension on the substrate profile of fast and slow skeletal muscle fiber types (1991) Med. Sci. Sports Exerc 1991; 23:121.

17. Caiozzo V, Haddad F, Baker M, Herrick R, Prietto N, Baldwin K. Microgravity-induced transformations of myosin isoforms and contractile properties of skeletal muscle. J Appl Physiol 1996; 81:123-32.

18. Fitts RH. Cellular mechanisms of muscle fatigue. Physiol Rev 1994; 74:49-94.

19. Henriksen EJ, Kirby CR, Tischler ME. Glycogen supercompensation in rat soleus muscle during recovery from nonweight bearing. J Appl Physiol 1989; 66:2782-7.
20. Henriksen EJ, Tischler ME. Glucose uptake in rat soleus: effect of acute unloading and subsequent reloading. J Appl Physiol 1988; 64:1428-32.

21. Fitts RH, Brimmer CJ, Heywood-Cooksey A, Timmerman RJ. Single muscle fiber enzyme shifts with hindlimb suspension and immobilization. Am J Physiol Cell Physiol 1989; 256:1082-91.

22. Thomason DB, Herrick RE, Surdyka D, Baldwin KM. Time course of soleus muscle myosin expression during hindlimb suspension and recovery. J Appl Physiol 1987; 63:130-6.

23. Tavitova MG, Fokina NM, Shenkman BS. Content of energy substrates in fibers of postural muscle soleus and its antagonist in the condition of support deprivation. Aviakosm Ekolog Med 2011; 45(1):55-9.

24. Tischler ME, Henriksen EJ, Munoz KA, Stump CS, Woodman CR, Kirby CR. Spaceflight on STS-48 and earthbased unweighting produce similar effects on skeletal muscle of young rats. J Appl Physiol 1993; 74:2161-5.

25. Riley DA, Ellis S, Slocum GR, Satyanarayana T, Bain JL, Sedlak FR. Hypogravity-induced atrophy of rat soleus and extensor digitorum longus muscles. Muscle Nerve 1987, 10:560-8.

26. Chi MM, Choksi R, Nemeth P, Krasnov I, Ilyina-Kakueva E, Manchester JK, et al. Effects of microgravity and tail suspension on enzymes of individual soleus and tibialis anterior fibers. J Appl Physiol 1992; 73:66-73.

27. Grichko VP, Heywood-Cooksey A, Kidd KR, Fitts RH. Substrate profile in rat soleus muscle fibers after hindlimb unloading and fatigue. J Appl Physiol 2000; 88:473-8.

28. Grichko VP, Gettelman GJ, Widrick JJ, Fitts RH. Substrate and enzyme profile of fast and slow skeletal muscle fibers in rhesus monkeys. J Appl Physiol 1999; 86:335-40.

29. Tsintzas OK, Williams C, Boobis L, Greenhaff P. Carbohydrate ingestion and glycogen utilization in different muscle fibre types in man. J Physiol 1995; 489:243-50.

30. Fitts RH, Riley DR, Widrick JJ. Microgravity and skeletal muscle. J Appl Physiol 2000; 89:823-39

31. Grichko V, Fitts RH. Effect of 17 day bedrest on the enzyme and metabolite profile of the slow type I fiber. Med Sci Sports Exerc 1996; 28:146.

32. Stein TP, Leskiw MJ, Schluter MD, Donaldson MR, Larina IM. Protein kinetics during and after long term space flight on MIR. Am J Physiol 1999; 276:E1014-21.

33. Stein TP, Leskiw MJ, Schluter MD, Hoyt RW, Lane HW, Gretebeck RE, et al. Energy expenditure and balance during spaceflight on the space shuttle. Am J Physiol 1999; 276:1739-48.

34. Musacchia XJ, Steffen JM, Fell RD, Dombrowski MJ, Oganov VS, Ilyina-Kakueva EI. Skeletal muscle atrophy in response to 14 days of weightlessness: vastus medialis. J Appl Physiol 1992; 73:44-50.

35. Mailian ES, Buravkova LB, Kokoreva LV. Energy reactions in the skeletal muscles of rats after a flight on the Kosmos-1129 biosatellite. Kosm Biol Aviakosm Med 1983; 17(3):32-6.

36. Belozerova IN, Nemirovskaya TL, Shenkman BS. Structural and metabolic profile of rhesus monkey $\mathrm{m}$. vastus lateralis after spaceflight. J Grav Physiol 2000; 7:55-8.

37. Krieger DA, Tate CA, McMillin-Wood J, Booth FW. Populations of rat skeletal muscle mitochondria after exercise and immobilization. J Appl Physiol 1980; 48:23-8.

38. Ogneva IV, Veselova OM, Larina IM. Changes in 
cell respiration of postural muscle fibers under longterm gravitational unloading after dietary succinate supplementation. Biofizika 2011; 56(1):122-8.

39. Yajid F, Mercier JG, Mercier BM, Dubouchaud H, Prefaut C. Effects of $4 \mathrm{wk}$ of hindlimb suspension on skeletal muscle mitochondrial respiration in rats. J Appl Physiol 1998; 84:479-85.

40. Ohira Y, Yasui W, Kariya F, Wakatsuki T, Nakamura K, Asakura T, et al. Metabolic adaptation of skeletal muscles to gravitational unloading. Acta Astronaut 1994; 33: 113-7.

41. Oishi Y, Ogata T, Yamamoto KI, Terada M, Ohira T, Ohira $\mathrm{Y}$, et al. Cellular adaptations in soleus muscle during recovery after hindlimb unloading. Acta Physiol 2008; 192:381-95.

42. Saks VA, Kuznetsov AV, Khuchua ZA, Vasilyeva EV, Belikova JO, Kesvatera T, et al. Control of cellular respiration in vivo by mitochondrial outer membrane and by creatine kinase. A new speculative hypothesis: possible involvement of mitochondrial-cytoskeleton interactions. J Mol Cell Cardiol 1995; 27:625-45.

43. Kay L, Li Z, Mericskay M, Olivares J, Tranqui L, Fontaine $\mathrm{E}$, et al. Study of regulation of mitochondrial respiration in vivo. An analysis of influence of ADP diffusion and possible role of cytoskeleton. Biochim Biophys Acta 1997; 1322:4159.

44. Milner DJ, Mavroidis M, Weisleder N, Capetanaki Y. Desmin cytoskeleton linked to muscle mitochondrial distribution and respiratory function. J Cell Biol 2000; 150(6):1283-98.

45. Georgatos SD, Maison C. Integration of intermediate filaments into cellular organelles. Int Rev Cytol 1996; 164:91138.

46. Capetanaki Y, Bloch RJ, Kouloumenta A, Mavrodis M, Psarras S. Muscle intermediate filaments and their links to membranes and membranous organelles. Exp Cell Res 2007; 313:2063-76.

47. Ogneva IV. Transversal stiffness and beta-actin and alphaactinin-4 content of the $\mathrm{m}$. Soleus fibers in the conditions of a 3-day reloading after 14-day gravitational unloading. J Biomed Biotechnol 2011; article ID 393405.

48. Mirzoev TM, Biriukov NS, Veselova OM, Larina IM, Shenkman BS, Ogneva IV. Desmin content and cell breathing in rats' $\mathrm{m}$. soleus fibers after 3- and 7-day recovery from 14day suspension. Aviakosm Ekolog Med 2012; 46(1):41-6.

49. Ogneva IV, Mirzoev TM, Biryukov NS, Veselova OM, Larina IM. Structure and functional characteristics of rat's left ventricle cardiomyocytes under antiorthostatic suspension of various duration and subsequent reloading. J Biomed Biotechnol 2012; article ID 659869.

50. Ogneva IV. Cell mechanosensitivity: mechanical properties and interaction with gravitational field. BioMed Research International 2013; article ID 598461.

51. Goffart S, Franko A, Clemen ChS, Wiesner RJ. a-Actinin 4 and BAT1 interaction with the Cytochrome c promoter upon skeletal muscle differentiation. Curr Genet 2006; 49:125-35.

52. Henriksen EJ, Tischler ME, Johnson DG. Increased response to insulin of glucose metabolism in the 6-day unloaded rat soleus muscle. J Biol Chem 1986; 261, 1070712.

53. Hikida RS, Gollnick PD, Dudley GA, Convertino VA, Buchanan P. Structural and metabolic characteristics of human skeletal muscle following 30 days of simulated microgravity. Aviat Space Environ Med 1989; 60:664-70.

54. Macho L, Nemeth S, Strbak V. The activity of certain liver enzymes and processes of lipogenesis in adipose tissue. In: The Effect of Dynamic Space Flight Factors on the Animal Body. Moscow; 1979:54-58.

55. Macho L, Nemeth S, Palkovics M, Strbak V, Tigranian RA. Enzymatic activity in the liver and lipogenesis processes in the fatty tissue of rats after a space flight. Kosm Biol Aviakosm Med 1980; 14(3):26-9.

56. Popova IA, Grigor'ev AI. The effect of space flight on metabolism: the results of biochemical research in rat experiments on the Kosmos biosatellites. Aviakosm Ekolog Med 1992; 26(5):4-10.

57. Cortes CW, Thompson PD, Moyna NM, Schluter MD, Leskiw MJ, Donaldson MR, et al. Protein kinetics in stable heart failure patients. J Appl Physiol 2003; 94:295-300.

58. Ferrando AA, Lane HW, Stuart CA, Davis-Street J, Wolfe RR. Prolonged bed rest decreases skeletal muscle and whole body protein synthesis. Am J Physiol (Endocrinol Metab) 1996; 270:E627-33.

59. Gibson JN, Halliday D, Morrison WL, Stoward PJ, Hornsby GA, Watt PW, et al. Decrease in human quadriceps muscle protein turnover consequent upon leg immobilization. Clin Sci 1987; 72:503-9.

60. Schonhyder F, Heilskov NS, Olesen K. Isotopic studies on the mechanism of negative nitrogen balance produced by immobilization. Scand J Clin Lab Invest 1954; 6:178-88.

61. Stein TP, Wade CE. Metabolic Consequences of Muscle Disuse Atrophy. J Nutr 2005; 135:1824-8.

62. Stump CS, Balon TW, Tipton CM. Effects of insulin and exercise on rat hindlimb muscles after simulated microgravity. J Appl Physiol 1992; 73:2044-53.

63. Campione M, Ausoni S, Guezennec CY, Schiaffino $\mathrm{S}$. Myosin and troponin changes in rat soleus muscle after hindlimb suspension. J Appl Physiol 1993; 74:1156-60.

64. Desplanches D. Structural and functional adaptations of skeletal muscle to weightlessness. Int J Sports Med 1997; 18(4S):S259-64.

65. Stump CS, Tipton CM, Henriksen EJ. Muscle adaptations to hindlimb suspension in mature and old Fischer 344 rats. J Appl Physiol 1997; 82:1875-81.

66. Winder WW. Energy-sensing and signaling by AMPactivated protein kinase in skeletal muscle. J Appl Physiol 2001; 91:1017-28.

67. Popova IA, Morukov BV, Arzamazov GS, Vetrova EG, Delenian NV. Metabolic characteristics during 120-day head-down tilt hypokinesia. Kosm Biol Aviakosm Med 1988; 22(2):40-5.

68. Abraham S, Lin CY, Klein HP, Volkmann C, Tigranyan RA, Vetrova EG. Studies of specific hepatic enzymes involved in the conversion of carbohydrates to lipids in rats exposed to prolonged spaceflight aboard Cosmos 1129. Physiologist 1980; 23(S6):S55-62.

69. Abraham S, Klein HP, Lin CY, Volkmann C. The effects of space flight on some rat liver enzymes regulating carbohydrate and lipid metabolism. Adv Space Res 1981; 1(14):199-217.

70. Ilyina-Kakueva EI, Petrova NV, Portugalov VV. Effect of spaceflight on skeletal muscle and the nervous apparatus of muscle. In: The Effect of Dynamic Space Flight Factors on the Animal Body. Moscow; 1979:95-104.

71. Ilyin EA, Kaplanskii AS. Comparative analysis of changes in rats organisms exposed to micrigravity and headdown suspension. Aviakosm Ecolog Med 1998; 32(6): 43-50. 72. Delenian NV, Markin AA. Status of the lipid peroxidation system in the tissues of rats following a 7-day flight on the 
Kosmos-1667 biosatellite. Kosm Biol Aviakosm Med 1989; 23(4):34-7.

73. Acher I, Tigranyan RA, Ahlersova E. The effect of microgravity on lipids of rats plasma and tissues. In: The Effect of Dynamic Space Flight Factors on the Animal Body. Moscow; 1979:58-60.

74. Nesterov VP, Zheludkova ZP, Kuznetcova LA. Glycogen synthase activity, glycogen phosphorylase, glycogen content and electrolyte composition of skeletal muscle.In: The Effect of Dynamic Space Flight Factors on the Animal Body. Moscow; 1979:114-117.

75. Rokhlenko KD. Electron microscopic study of skeletal muscles during hypokinesia. Moscow, 1977.

76. Tigranian RA, Beliakova MI, Kalita NF, Popova IA. Changes of biochemical parameters of the blood. In: The Effect of Dynamic Space Flight Factors on the Animal Body. Moscow; 1979:41-44.

77. Thornton WE, Moore TP, Pool SL. Fluid shifts in weightlessness. Aviat Space Environ Med 1987; 58:A86-90.

78. Watenpaugh DE, Hargens AR. The cardiovascular system in microgravity. Handbook of Physiology Environmental Physiology Am Physiol Soc 1996; I.3(29):631-74.

79. Nixon JV, Murray RG, Bryant C, Johnson RLJr, Mitchell JR, Holland OB, et al. Early cardiovascular adaptation to simulated zero gravity. J Appl Physiol 1979; 46:541-8.

80. Bungo MW, Goldwater DJ, Popp RL, Sandler H. Echocardiographic evaluation of space shuttle crewmembers. J Appl Physiol 1987; 62:278-83.

81. Charles JB, Lathers CM. Cardiovascular adaptation to spaceflight. J Clin Pharmacol 1991; 31:1010-23.

82. Morey ER, Sabelman EE, Turner RT, Baylink DJ. A new rat model simulating some aspects of space flight. Physiologist 1979; 22(6):S23-6.

83. Morey-Holton E, Globus RK, Kaplansky A, Durnova $\mathrm{G}$. The hindlimb unloading rat model: literature overview, technique update and comparison with space flight data. Adv Space Biol Med 2005; 10:7-40.

84. Hargens AR, Steakai J, Johansson C, Tipton CM. Tissue fluid shift, forelimb loading, and tail tension in tailsuspended rats. Physiologist 1984; 27:S37-8.

85. McDonald KS, Delp MD, Fitts RH. Effect of hindlimb unweighting on tissue blood flow in the rat. J Appl Physiol 1992; 72:2210-8.

86. Shellock FG, Swan HJ, Rubin SA. Early central venous pressure changes in the rat during two different levels of headdown suspension. Aviat Space Environ Med 1985; 56:791-5.

87. Halet G, Viard P, Morel J-L, Mironneau J, Mironneau Ch.
Effects of hindlimb suspension on cytosolic Ca21 and [3H] ryanodine binding in cardiac myocytes. Am J Physiol (Heart Circ Physiol 45) 1999; 276:H1131-6.

88. Kunishima T. Ultrastructural and biochemical enzymatic properties of right ventricular muscles during hindlimb suspension in rats. Nihon Seirigaku Zasshi 1993; 55(4):153-164. 89. Bigard AX, Boehm E, Veksler V, Mateo P, Anflous K, Ventura-Clapier R. Muscle unloading induces slow to fast transitions in myofibrillar but not mitochondrial properties. Relevance to skeletal muscle abnormalities in heart failure. J Mol Cell Cardiol 1998; 30:2391-401.

90. Yin W, Liu J-C, Fan R, Sun X-Q, Ma J, Feng N, et al. Modulation of beta-adrenoceptor signaling in the hearts of 4-wk simulated weightlessness rats. J Appl Physiol 2008; 105:569-74.

91. Cui Y, Zhang S-M, Zhang Q-Y, Fan R, Li J, Guo H-T, et al. Modulation of intracellular calcium transient in response to beta-adrenoceptor stimulation in the hearts of 4-wk-old rats during simulated weightlessness. J Appl Physiol 2010; 108:838-44.

92. Fagette S, Ming L, Claude Gh, Gauquelin G. Cardiovascular variability and baroreceptor reflex sensitivity over a 14-day tail suspension in rats. J Appl Physiol 1995; 78(2):717-724.

93. Chen J, Zhang LF, Ma J. Ultrastructural changes of myocardium in long-term tail-suspended rats. J Chinese Aerospace Med 1995; 6:133-7.

94. Zhang LF, Yu ZB, Ma J. Functional alterations in cardiac muscle after medium or long term simulated weightlessness and related cellular mechanisms. J Gravit Physiol 1995; 2:5-8. 95. Yu Zh-B, Bao J-X, Ma J, Zhang L-F, Jin J-P. Changes in myocardial contractility and contractile proteins after four weeks of simulate weightlessness in rats. J Gravit Physiol 2000; 7(2):P147-8.

96. Overton JM, Woodman CR, Tipton CM. Effect of hindlimb suspension on $\mathrm{V}^{\bullet} \mathrm{O} 2$ max and regional blood flow responses to exercise. J Appl Physiol 1989; 66:653-9.

97. LeBlanc AD, Schneider VS, Shakelford L, West V, Oganov $\mathrm{V}$, Bakulin L, et al. Bone mineral and lean tissue loss after long duration space flight. J Bone Miner Res 1996, 11:S323.

98. Matsumoto A, Storch KJ, Stolfi A, Mohler SR, Frey MA, Stein TP. Weight loss in humans in space. Aviat Space Environ Med 2011; 82(6):615-35.

99. Stein TP. Weight, muscle and bone loss during space flight: another perspective. Eur J Appl Physiol 2013; 113:2171-81.

100. Stein TP. The relationship between dietary intake, exercise, energy balance and the space craft environment. Pflugers Arch 2000; 441:R21-31. 